\title{
The Utilization of Waste Seashell for High Temperature Desulfurization
}

\author{
Young Sik Kim · Sung Chul Hong ${ }^{\dagger}$ \\ Department of Regional Environmental System Engineering, Pusan National University, \\ Miryang 627-706, Korea \\ (Received February 10, 2010/Revised February 28, 2010/Accepted March 25, 2010)
}

\begin{abstract}
The integrated gasification combined cycle (IGCC) is one of the most promising proposed processes for advanced electric power generation that is likely to replace conventional coal combustion. This emerging technology will not only improve considerably the thermal efficiency but also reduce or eliminate the environmentally adverse effects normally associated with coal combustion. The IGCC process gasifies coal under reducing conditions with essentially all the sulfur existing in the form of hydrogen sulfide $\left(\mathrm{H}_{2} \mathrm{~S}\right)$ in the product fuel gas. The need to remove $\mathrm{H}_{2} \mathrm{~S}$ from coal derived fuel gases is a significant concern which stems from stringent government regulations and also, from a technical point of view and a need to protect turbines from corrosion. The waste seashells were used for the removal of hydrogen sulfide from a hot gas stream. The sulphidation of waste seashells with $\mathrm{H}_{2} \mathrm{~S}$ was studied in a thermogravimetric analyzer at temperature between $600^{\circ} \mathrm{C}$ and $800^{\circ} \mathrm{C}$. The desulfurization performance of the waste seashell sorbents was experimentally tested in a fixed bed reactor system. Sulfidation experiments performed under reaction conditions similar to those at the exit of a coal gasifier showed that preparation procedure and technique, the type and the amount of seashell, and the size of the seashell affects the $\mathrm{H}_{2} \mathrm{~S}$ removal capacity of the sorbents. The pore structure of fresh and sulfided seashell sorbents was analyzed using mercury porosimetry, nitrogen adsorption, and scanning electronmicroscopy.
\end{abstract}

Keywords: seashell sorbents, sulphidation, desulfurization

\section{Introduction}

The reactions of hydrogen sulfide with various metal oxides have been investigated extensively in connection with the desulfurization of coal gas to be used in advanced power generation cycles. ${ }^{1)}$ Although hydrogen sulfide removal can be carried out at ambient temperatures by established liquid absorption processes, desulfurizations by reaction with metal oxides at high temperatures can improve considerably the economy of power generation. Thermodynamic calculations have shown that the oxides of the metals such as $\mathrm{Ca}, \mathrm{Fe}, \mathrm{Co}, \mathrm{Cu}$ and $\mathrm{Zn}$ can be used as sulphur sorbents to be applied

Corresponding author: Department of Regional Environmental System Engineering, Pusan National University Tel: 82-55-350-5433, Fax: 82-55-350-5439

E-mail: schong@pusan.ac.kr for high-temperature coal gas desulphurization., ${ }^{2,3)}$ On basis of these metals, many sorbents have been developed. One can roughly discriminate between synthetic sorbents which are relatively expensive but have a long lifetime, and natural sorbents which are cheap but possibly less stable. Sorbents that belong to the category of natural sorbents are iron ore, limestone and seashells, either in raw or calcined form. ${ }^{4}$

The objective of this study is the evaluation of the desulfurization performance of seashell sorbents in a fixed bed reactor. Seashell sorbents were tested under reaction conditions that are typical for hot coal gas streams. Experiments were carried out to study the parameters that affect the $\mathrm{H}_{2} \mathrm{~S}$ removal ability of a seashell sorbents. In addition to the sulfidation experiments, the pore structure of reacted and sulfided sorbents was analyzed. 


\section{Materials and Method}

Four samples of seashell such as oyster, clam, short-necked clam and hard shelled mussel were the solid reactants of this study. A Norelco intermittent diffractometer employing Ni-filtered $\mathrm{Cu}$ radiation was used for qualitative chemical analysis of the components present in a sample. X-ray powder diffraction patterns were obtained in a $2 \theta$ range of $25-40^{\circ}$, which enabled detection of various phases. Seashell sorbents were examined by an ETEC Corporation electron microscope operating at $20 \mathrm{kV}$ with resolution of $70 \AA$. A Perkin Elmer thermogravimetric analyzer (TGA7) interfaced through an analog-to-digital converter to a computer served to measure the sample weight continuously. The quartz housing and flow path of the TGA were modified so that the system could accommodate corrosive gases such as $\mathrm{H}_{2} \mathrm{~S}$. A gas flow of $30 \mathrm{ml} / \mathrm{min}$ was used for both the protective $\mathrm{N}_{2}$ back flow and the feed. $A \mathrm{~N}_{2}$ gas was used for reduction runs, a $3 \% \mathrm{H}_{2} \mathrm{~S}$ in $\mathrm{N}_{2}$ mixture was used for sulfidation runs. Typically, a $45 \mathrm{mg}$ sample of particles, 10/100 mesh, was employed.

The rector consist of a quartz tube of $1 / 8$ inch i.d. and 8 inch length loaded to a bed height of 4 inch with a sorbent granules (10/100 mesh). The reactor tube was mounted vertically inside an electric furnace, and the bed temperature was

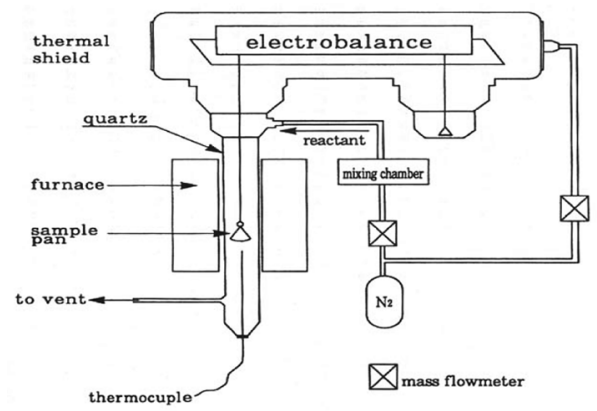

monitored by a K-type thermocouple moving inside a quartz thermowell concentric to the reactor tube. In a typical sulfidation run, seashell sorbents was exposed to feed gas containing $99 \% \mathrm{~N}_{2}$ and $1 \%$ $\mathrm{H}_{2} \mathrm{~S}$, at a constant temperature of $600-800^{\circ} \mathrm{C}$. Feed gas rate of a $200 \mathrm{~cm}^{3} / \mathrm{min}$ (STP) was typically used.

\section{Results and Discussion}

The desulfurization performance of seashell depends on the nature and physicochemical properties of the sorbents and the composition of the reactive gas.

Limestone and waste shell were mostly consisted of $\mathrm{CaCO}_{3}$ and rest of components were similar. Final calcinations temperature were completed at $780^{\circ} \mathrm{C}, 850^{\circ} \mathrm{C}$ for oyster, natural limestone respectively. Another waste shell were calcinated at 810 $830^{\circ} \mathrm{C}$.

XRD analysis to identify major components before and after calcination and product $\mathrm{CaS}$, showed that maximum intensity peak of precalcinated samples mostly consist of $\mathrm{CaCO}_{3}$ were occurred $2 \theta$ was $31^{\circ}$. In the case of the samples after calcinations, $\mathrm{CaCO}_{3}$ was converted into $\mathrm{CaO}$, so this was observed at $37^{\circ}$. After sulfurization maximum intensity peak of $\mathrm{CaS}$ was observed at $32^{\circ}$.

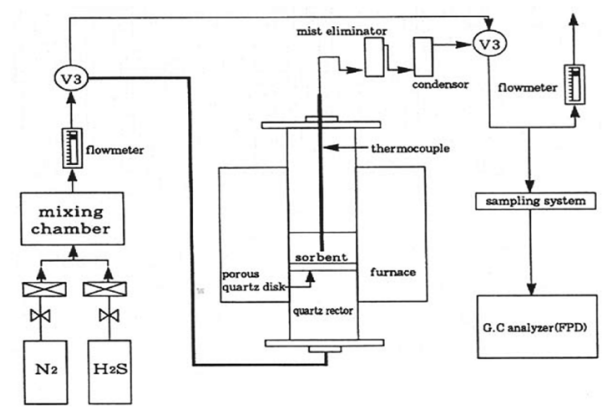

Fig. 1. Schematic diagram of the experimental apparatus.

Table 1. Specific surface area of $\mathrm{CaCO}_{3}$ and $\mathrm{CaO}$ for limestone and seashells

\begin{tabular}{|c|c|c|c|c|c|}
\hline Sorbent & Limestone & Oyster & Clam & $\begin{array}{l}\text { Short-necked } \\
\text { clam }\end{array}$ & $\begin{array}{c}\text { Hard shelled } \\
\text { mussel }\end{array}$ \\
\hline Specific surface area of $\mathrm{CaCO}_{3}\left(\mathrm{~m}^{2} / \mathrm{g}\right)$ & 0.236 & 2.447 & 2.157 & 2.002 & 1.690 \\
\hline Specific surface area of $\mathrm{CaO}\left(\mathrm{m}^{2} / \mathrm{g}\right)$ & 1.154 & 2.121 & 0.765 & 0.537 & 0.733 \\
\hline
\end{tabular}




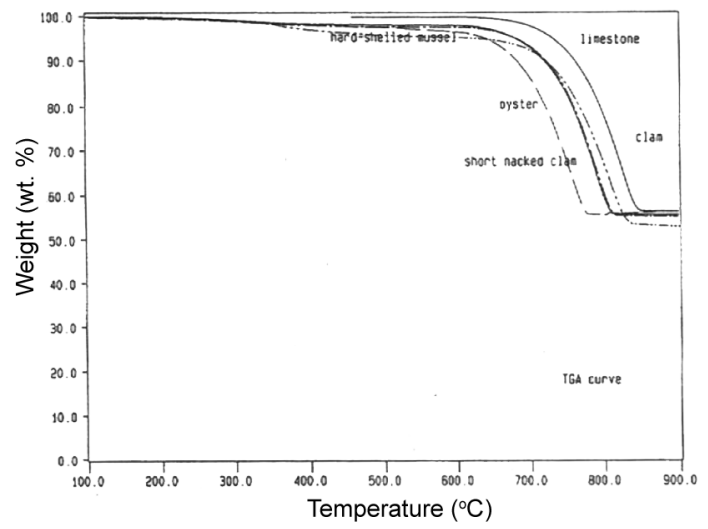

Fig. 2. TGA profile of seashells and limestone.

According to SEM/BET analysis were investigated pore distribution and surface area of particles. Additive pores were formed after calcinations. Also, small grains were formed after sulfurization. BET surface area of limestone, oyster, clam before calcinations were $0.2363,2.4465,1.69 \mathrm{~m}^{2} / \mathrm{g}$, and after calcinations were $1.1543,2.1209,2.17 \mathrm{~m}^{2} / \mathrm{g}$, respectively.

TGA results showed that activation energy of desulfurization sorbents were about 167-207 kJ/ mole. Short-nacked shell and oyster had lower activation energy. This means that energy requirement was low in the calcinations. And, $\mathrm{CaCO}_{3}$ was converted into $\mathrm{CaO}$. Reaction velocity and order of hard-shelled mussel was the highest.

According to TGA results, temperature influenced on $\mathrm{H}_{2} \mathrm{~S}$ removal efficiency. As desulfurization temperature increased, desulfurization efficiency increased. Also, maximum desulfurization efficiency was observed at $800^{\circ} \mathrm{C}$. Desulfurization was related to calcinations temperature. Considering temperature ranges of exhausted gas from hot gas gasification equipment were $400-800^{\circ} \mathrm{C}$. Thus, desulfurization efficiency would be increased desulfurization temperature situation at highly.

Experiments by TGA showed that particle size of sorbents had influenced on desulfurization capacity. Maximum desulfurization capacity was observed at $0.631 \mathrm{~mm}$ for oyster and clam. Rest of sorbents showed similar capacity within 0.171 $0.335 \mathrm{~mm}$ particle size range. So, particle size would be considered.

Fixed bed desulfurization experiments, to obtain basic data for scale-up was indicated. Oyster was the best among the various sorbents, like the results of TGA. Especially, $\mathrm{H}_{2} \mathrm{~S}$ removal efficiency of uncalcined oyster was the highest. When using oyster as desulfurization sorbents, calcinations process was not needed. Thus, desulfurization efficiency would be expected.

Fixed bed reactor experiments were influenced particle size of sorbents on desulfurization capacity. As smaller particle size was found better desulfurization capacity. Large capacity difference was found between $0.631 \mathrm{~mm}$ and $0.335 \mathrm{~mm}$. But, differences between $0.335 \mathrm{~mm}$ and $0.241 \mathrm{~mm}$ was relatively small. As bed temperature increased,

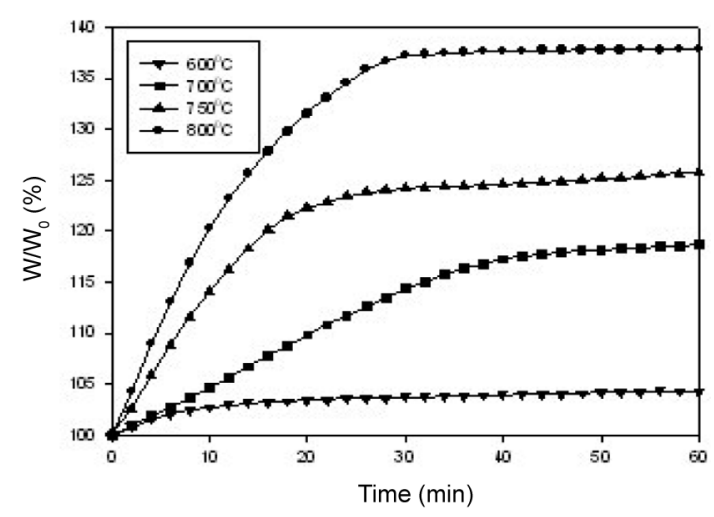

Fig. 3. Effect of temperature on sulfidation of oyster.

Table 2. TGA kinetics of seashells and limestone

\begin{tabular}{lccc}
\hline \hline \multicolumn{1}{c}{ Sorbents } & $\begin{array}{c}\text { Activation Energy Ea. } \\
\mathrm{KJ} / \mathrm{mole}\end{array}$ & $\begin{array}{c}\text { Reation Velocity } \ln (\mathrm{Z}) \\
\sec ^{-1}\end{array}$ & Reaction Order, $\mathrm{n}$ \\
\hline Limestone & $201.72 \pm 5.17$ & $16.47 \pm 0.63$ & $0.37 \pm 0.08$ \\
Oyster & $176.10 \pm 8.90$ & $15.07 \pm 1.14$ & $0.42 \pm 0.10$ \\
Clam & $19.37 \pm 2.05$ & $16.27 \pm 0.26$ & $0.44 \pm 0.04$ \\
Short necked clam & $166.51 \pm 0.24$ & $12.97 \pm 0.03$ & $0.14 \pm 0.01$ \\
Hard-shelled mussel & $206.79 \pm 4.11$ & $17.59 \pm 0.50$ & $0.74 \pm 0.06$ \\
\hline
\end{tabular}




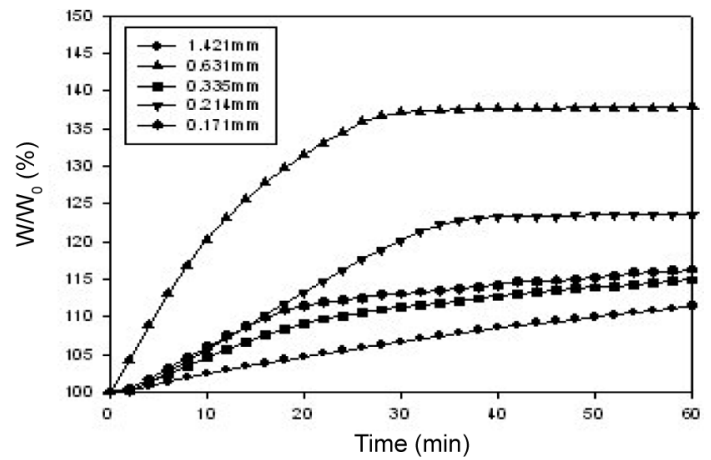

Fig. 4. Effect of particle size on sulfidation of oyster.
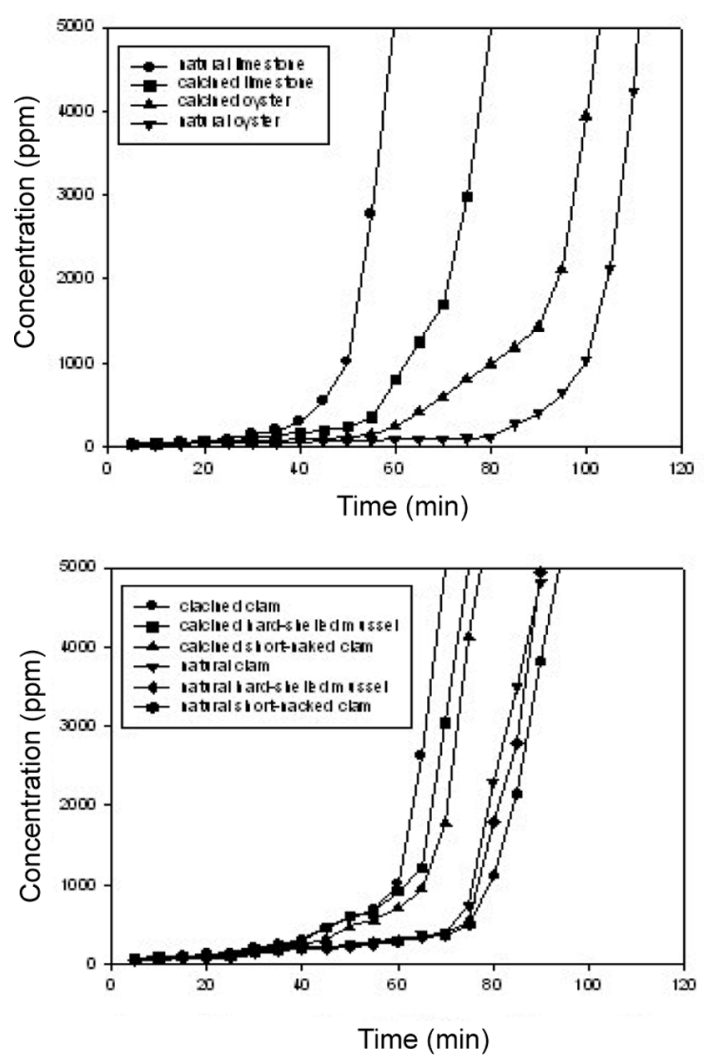

Fig. 5. $\mathrm{H}_{2} \mathrm{~S}$ removal efficiency for sulfidation of seashells.

$\mathrm{H}_{2} \mathrm{~S}$ removal capacity increased. Therefore, both particle size and bed temperature should be considered to remove $\mathrm{H}_{2} \mathrm{~S}$ by sorbents.

Unreacted core model $^{5)}$ for desulfurization rate prediction of sorbent was indicated. These were linear relationship between time and conversion. So cocurrent diffusion resistance was conducted

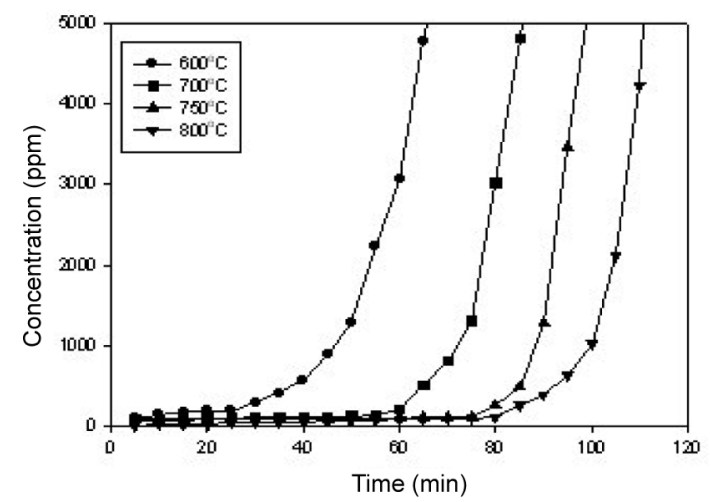

Fig. 6. Effect of temperature on $\mathrm{H}_{2} \mathrm{~S}$ breakthrough for sulfidation of oyster.

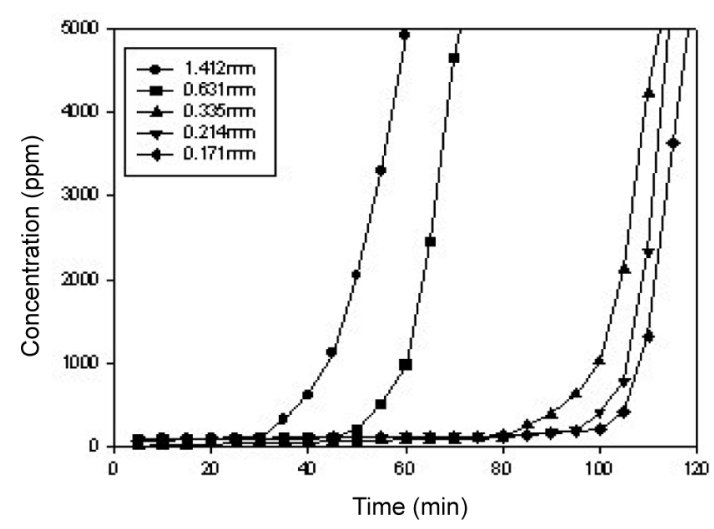

Fig. 7. Effect of particle size on $\mathrm{H}_{2} \mathrm{~S}$ breakthrough for sulfidation of oyster.

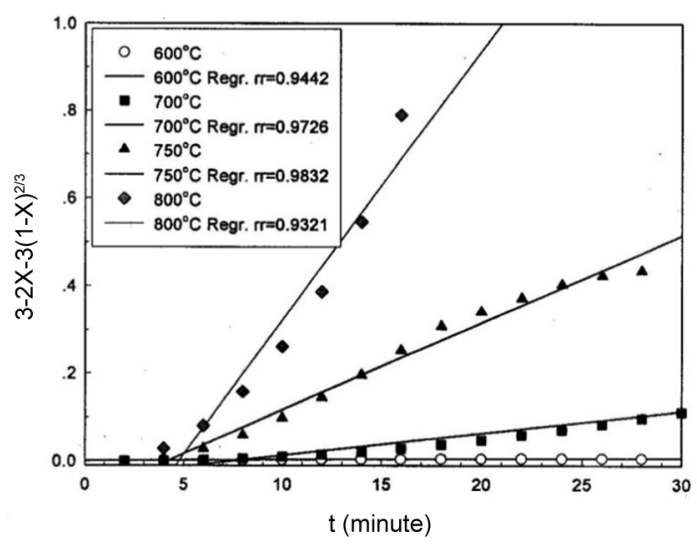

Fig. 8. Reaction rate data for sulfidation of oyster at 600 $800^{\circ} \mathrm{C}$. 
reaction rate controlling step as follows :

$$
\begin{aligned}
& y=0.0609 X-0.02806\left(\text { at } 800^{\circ} \mathrm{C}\right) \\
& y=0.0197 X-0.0725\left(\text { at } 750^{\circ} \mathrm{C}\right) \\
& y=5.0063 \times 10^{-3} X-0.0372\left(\text { at } 700^{\circ} \mathrm{C}\right) \\
& y=1.9321 \times 10^{-4} X-1.0650 \times 10^{-3}\left(\text { at } 600^{\circ} \mathrm{C}\right)
\end{aligned}
$$

where, $x=$ reaction time

$$
y=\text { reaction rate }
$$

\section{Conclusion}

BET surface area of limestone, oyster and clam before calcinations were $0.2363,2.4465,1.69 \mathrm{~m}^{2} /$ $\mathrm{g}$, and after calcinations were 1.1543, 2.1209, 2.17 $\mathrm{m}^{2} / \mathrm{g}$, respectively. XRD analysis to identify major components before and after calcination and product $\mathrm{CaS}$, showed that maximum intensity peak of precalcinated samples mostly consist of $\mathrm{CaCO}_{3}$ were occurred $2 \theta$ was $31^{\circ}$.

According to TGA results, temperature influenced on $\mathrm{H}_{2} \mathrm{~S}$ removal efficiency. As desulfurization temperature increased, desulfurization efficiency increased. Also, maximum desulfurization efficiency was observed at $800^{\circ} \mathrm{C}$. Maximum desulfurization capacity was observed at $0.631 \mathrm{~mm}$ for oyster and clam. Rest of sorbents showed similar capacity within $0.171-0.335 \mathrm{~mm}$ particle size range. As smaller particle size was found better than desulfurization capacity. Large capacity difference was found between $0.631 \mathrm{~mm}$ and $0.335 \mathrm{~mm}$. But, differences between $0.335 \mathrm{~mm}$ and $0.241 \mathrm{~mm}$ was relatively small. As bed temperature increased, $\mathrm{H}_{2} \mathrm{~S}$ removal capacity increased.

Unreacted core model for desulfurization rate prediction of sorbent was indicated. These were linear relationship between time and conversion.

\section{Acknowledgements}

This work was supported for two years by Pusan National University Research Grant.

\section{References}

1. Abbasin, J. A., Rehmat, D, Leppin and Bannerjee, D. : $\mathrm{H}_{2} \mathrm{~S}$ removal from fuel gas during coal gasfication. Paper American Chemistry Society, Division Fuel Chemistry, 35, 196-206, 1990.

2. Barin, I., Knacke, O. and Kybaschewski, O. : Thermochemical Properities of Inorganic Substances Supplement. NewYork, Springer-Verlag, 115-120, 1976

3. Borgwardt, R. H. : Kinetics of reaction of $\mathrm{SO}_{2}$ with calcined limestone. Environmental Science and Technology, 4, 59-64, 1970.

4. Levenspiel, O. : Chemical Reaction Engineering $2^{\text {nd }}$ ed. NewYork, John Wiley \& Sons Inc., 85-95, 2007.

5. Patrick, V., Gavalas, G. R. and Sharma, P. K. : Reduction and generation of mixed iron-aluminum oxide sorbents. Indistrial Chemical Reserach, 32 , 519-532, 1993. 